\title{
Pellonraivauksen yhteydessä tehtävän kannonnoston suorat ja epäsuorat energiapanokset
}

\author{
Risto Lauhanen ${ }^{1 *}$, Jukka Ahokas² \& Jussi Esala ${ }^{1}$ \\ ${ }^{1}$ Seinäjoen ammattikorkeakoulu, Elintarvike ja maatalous, Ilmajoentie 525, FI-60800 Ilmajoki, \\ risto.lauhanen@seamk.fi; jussi.esala@seamk.fi \\ ${ }^{2}$ Helsingin yliopisto, Maataloustieteiden laitos, Koetilantie 5, FI-Helsinki, jukka.ahokas@outlook.com
}

\section{TIIVISTELMÄ}

Tutkimuksen tavoitteena oli selvittää pellonraivauksen yhteydessä nostettavien kantojen nettoenergiaa ja energiasuhdetta. Erityisesti Pohjanmaan maakuntien soita raivataan pelloiksi, koska karjatilat tarvitsevat lisää lannanlevitysalaa. Metsäyhtiöiden ohjeiden mukaan nostetut kannot voidaan hyödyntää energiantuotannossa suurilla voimalaitoksilla, ja maatilat saavat kannoista lisätuloja.

Energiataselaskelmat tehtiin erikseen kuusen kannoille ja männyn kannoille. Kantojen energiasisältöä verrattiin metsäkonetyön ja kantomateriaalin kaukokuljetuksen energiapanoksiin. Suorat energiapanokset perustuivat koneiden ja kuljetuskaluston polttoaineen kulutukseen. Laskentaketju määriteltiin pellonraivausalalta voimalaitokselle. Epäsuoriin energiapanoksiin sisällytettiin koneenvalmistuksen osuus.

Nettoenergia laskettiin vähentämällä kantojen energiasisällöstä hankintatyössä käytetyn polttoaineen energiasisältö. Energiasuhde saatiin jakamalla kantojen energiasisältö hankintatyössä käytetyn polttoaineen energiasisällöllä.

Peruslaskelmissa nettoenergia oli 446 - $698 \mathrm{GJ} \mathrm{ha}^{-1}$, ja energiasuhde $22-33$ suorien energiapanosten osalta. Kun epäsuorat energiapanokset otettiin huomioon, niin lukuarvot olivat vastaavasti 440 - $692 \mathrm{GJ} \mathrm{ha}^{-1}$, ja 17 - 26. Kannonnosto oli siten energiatehokasta.

Epäsuorien energiapanosten eli koneenvalmistuksen osuus jäi alhaiseksi, koska konekaluston vuotuinen käyttötuntimäärä oli korkea ja koneiden tekninen käyttöikä lyhyt. Koneiden huolto- ja korjaustöiden energiapanoksia ei voitu laskea, kun riittäviä laskentatietoja ei ollut käytössä. Tältä osin jatkossa tarvitaan uutta tutkimustietoa.

Tekijöiden alkuperäinen tutkimus on julkaistu vuonna 2015 sarjassa Agronomy Research 13(2): $348-353$.

Asiasanat: bioenergia, energiataselaskelmat, metsäkoneet, pellonraivaus, puuperäinen energia. 


\section{Johdanto}

Suomessa tarvitaan uutta viljelysmaata erityisesti Pohjanmaan maakuntien kotieläintiloilla. Vuosina 2000-2011 Suomessa raivattiin peltoa kaikkiaan 95000 hehtaaria lähinnä turvemaiden metsistä sekä vähäkivisistä kuusikoista (ks. Niskanen \& Lehtonen 2014).

Toisaalla EU:n keskeisenä tavoitteena on estää ilmastonmuutosta muun muassa uusiutuvan bioenergian käyttöä lisäämällä. Nuorten metsien pienpuuhake sekä kuusen uudistamisalojen hakkuutähdehake ja kantomurske ovat keskeiset metsäenergian lähteet (Hakkila, 2004, Laitila ym. 2012).

Suomessa kantoja ja juurakoita hankintaan biopolttoaineeksi suurille yli 5 MW:n kattilatehon laitoksille (Laurila \& Lauhanen 2010). Kantojen ja juurakoiden energiasisältö on $130-200 \mathrm{MWh} \mathrm{ha}^{-1}$ eli 468 - $720 \mathrm{GJ} \mathrm{ha}^{-1}$ (Hakkila 2004, Lauhanen ym. 2014).

Kannonnosto on tarpeen osana pellonraivausta. Mikäli kannot nostetaan oikealla tavalla, voi pellonraivaaja myydä ne metsä- tai energiayhtiölle (Lauhanen ym. 2014). Kantojen ja juurakoiden korjuun ympäristövaikutuksista ja energiatehokkuudesta on kuitenkin keskusteltu (Lauhanen ym. 2014). Metsäenergian suorien energiapanosten on laskettu olevan noin 2-4\% metsäbiopolttoaineen energiasisällöstä (Laitila ym. 2012). Metsäenergian hankinnan epäsuoria energiapanoksia ei ole kuitenkaan tutkittu toisin kuin maatalouspuolella (Mikkola \& Ahokas 2010).

Tutkimuksen tavoitteena oli selvittää pellonraivauskohteilta hankittavan kantoenergian suoria ja epäsuoria energiapanoksia Suomen olosuhteissa.

\section{Aineisto ja menetelmät}

Kantojen ja juurakoiden energiasisällöt saatiin aiemmista tutkimuksista (Hakkila 2004, Laurila \& Lauhanen 2010, Laitila ym. 2012). Kantojen ja juurakoiden hankinnan suorat energiapanokset perustuivat metsäkoneiden, kantomurskainten ja kaukokuljetuskaluston polttoaineen kulutukseen (Laitila ym. 2012). Epäsuorat energiapanokset perustuivat traktorin valmistuksen lukuarvoihin (Hakkila 1989, Mikkola \& Ahokas 2010).

Kantoenergian hankintaketju sisälsi kantojen noston kaivinkoneella, metsäkuljetuksen kuormatraktorilla, murskauksen metsäautotien varressa sekä kantomurskeen kaukokuljetuksen metsästä voimalaitokselle (Laurila \& Lauhanen 2007, Laitila ym. 2012). Murskaamattomien kantojen logistiikkaa ei tarkasteltu, koska pitkät kuljetusmatkat eivät ole järkeviä (ks. Hakkila 1989).

Männynkantojen energiasisältö oli $468 \mathrm{GJ} \mathrm{ha}^{-1}\left(=130 \mathrm{MWh} \mathrm{ha}^{-1}\right)$ (Hakkila 2004). Uudistusalan ainespuun hakkuukertymä oli silloin $260 \mathrm{~m}^{3} \mathrm{ha}^{-1}$. Kuusen uudistamisaloilla vastaavat lukuarvot olivat $720 \mathrm{GJ} \mathrm{ha}^{-1}$ (= $200 \mathrm{MWh} \mathrm{ha}^{-1}$ ). (Laurila \& Lauhanen 2010, Lauhanen ym. 2014). Tällöin tukin ja kuitupuun kertymä oli $400 \mathrm{~m}^{3}$ ha-1.

Laskelmissa työmaan eli pellonraivauskohteen pinta-ala oli 3,0 hehtaaria, jolloin kantojen ja juurakoiden energiasisältö oli 1512 - $2160 \mathrm{GJ} \mathrm{ha}^{-1}$ kasvupaikasta riippuen (turvemaan männikkö vs. kivennäismaan kuusikko). Kantojen noston tuottavuus oli 1,0 hehtaaria päivän työvuoroissa (Kuva 1) (Laurila \& Lauhanen 2007). Metsäkuljetuksen tuottavuus oli samoin 1,0 hehtaaria päivässä (Laurila \& Lauhanen 2007). Kantojen murskauksen tuottavuus oli 100 irtokuutiometriä käyttötunnissa (Lauhanen ym. 2014). Kantomurske kuljetettiin umpiautolla, jolloin keskimääräinen kaukokuljetusmatka metsäautotien varresta voimalaitokselle oli 45 kilometriä (Laitila ym. 2012). 


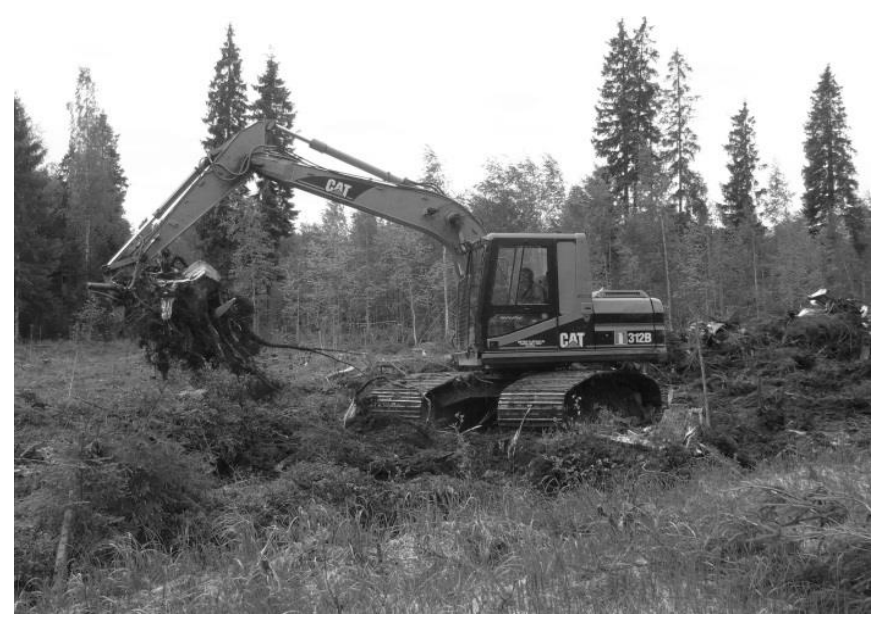

Kuva 1. Kaivinkone kannonnostossa turvemaalla (Kuva: Jussi Laurila).

Suorat energiapanokset perustuivat hankintaketjun metsäkoneiden, kantomurskaimen ja kaukokuljetuskaluston polttoaineen kulutukseen (Taulukot 1 ja 2) (Laitila ym. 2012, Lauhanen ym. 2014). Polttoaineen energiasisältö oli 35,1 MJ litraa kohti. Siten hankintaketjun suorat energiapanokset olivat 64,8 GJ metsästä voimalaitokselle laskettuna (Taulukko 1).

Hakkilan mukaan (1989) metsäenergian hankinnassa käytetyn traktorin epäsuorat energiapanokset olivat $158,9 \mathrm{MJ} \mathrm{kg}^{-1}$ eli massaa kohti laskettuna. Laskelmissa työkoneen massa $(\mathrm{kg})$ kerrottiin mainitulla Hakkilan (1989) soveltamalla lukuarvolla (kg). Sitten epäsuorat energiapanokset (GJ) jaettiin hankintaketjun koneyksikön teknistä käyttöikää kohti tunteina. Lukuarvo kerrottiin sitten työmaan (3,0 hehtaaria) konekohtaisilla työtuntimäärillä. Hankintakaluston teknisen käyttöiän oletettiin laskelmissa olevan 4,0 vuotta eli 12000 tuntia (Lauhanen ym. 2014). Metsäenergian hankinnassa työkoneella tehdään siis keskimäärin 3000 tuntia vuodessa (Laitila ym. 2010, Lauhanen ym. 2014).

Energiataselaskelmat laadittiin Mikkolan ja Ahokkaan (2010) esittämällä tavalla. Kantojen ja juurakoiden nettoenergia $\left(\mathrm{GJ} \mathrm{ha}^{-1}\right)$. saatiin vähentämällä niiden energiasisällöstä $\left(\mathrm{GJ} \mathrm{ha}^{-1}\right)$ hankintaketjun energiapanokset $\left(\mathrm{GJ} \mathrm{ha}^{-1}\right.$ ). Energiasuhde saatiin jakamalla kantojen ja juurakoiden energiasisältö niiden hankintaan käytetyillä energiapanoksilla (Mikkola \& Ahokas 2010). Laskelmat tehtiin sekä suorien että epäsuorien energiapanosten osalta.

Taulukko 1. Kantomurskeen hankintaketjussa käytetyn kone- ja kuljetuskaluston polttoaineen kulutukset. Työmaan pinta-ala oli 3,0 ha ja kaukokuljetusmatka metsästä voimalaitokselle $45 \mathrm{~km}$. Selitykset: Massa = koneyksikön tai auton massa tonneina, Aika = koneyksikön tai auton käyttötunnit työmaalla tai sitä kohti (3,0 ha) laskettuna, Kulutus = polttoaineen kulutus käyttötuntia kohtia (litraa/h), ja $\mathrm{W}=$ käytetyn polttoaineen energiasisältö (GJ). (Laitila ym. 2012, Lauhanen ym. 2014).

\begin{tabular}{lcccc} 
Konetyyppi & Massa & Aika & Kulutus & W \\
\hline Kaivinkone & 21 & 27 & 18 & 17,1 \\
Kuormatraktori & 10 & 27 & 12 & 11,4 \\
Kantomurskain & 36 & 9 & 65 & 20,5 \\
Kantoauto & 20 & 9 & 50 & 15,8 \\
\hline Yhteensä & 87 & 72 & 1845 & 64,8 \\
& & & & \\
\hline
\end{tabular}

Ennen kantojen ja juurakoiden nostoa pellonraivausalalta korjataan myös hakkuutähteet (Laitila ym. 2012). Hakkuutähteiden energiasisältö on $396-566 \mathrm{GJ} \mathrm{ha}^{-1}\left(=110-160 \mathrm{MWh}^{-1}\right)$. Koska hakkuutähteen kasaus tehdään yksioteharvesterilla ainespuuhakkuun yhteydessä, laskelmissa oletettiin sen energiapanokseksi 0,0 GJ ha' ${ }^{-1}$ (Taulukko 2) (Lauhanen ym. 2014). 
Taulukko 2. Hakkuutähdehakkeen hankintaketjun polttoaineen kulutus konetyyppien ja kuljetuskaluston osalta. Selitykset: Samat kuin taulukossa 1. (Laitila ym. 2012, Lauhanen ym. 2014).

\begin{tabular}{lcccc} 
Konetyyppi & Massa & Aika & Kulutus & W \\
\hline & & & & \\
Hakkuukone & 10 & 27 & 0 & 0,00 \\
Kuormatraktori & 10 & 27 & 12 & 11,37 \\
Murskain & 36 & 9 & 65 & 20,53 \\
Kantoauto & 20 & 9 & 50 & 15,80 \\
\hline Yhteensä & 76 & 72 & 1359 & 59,10 \\
& & & & \\
\hline
\end{tabular}

\section{Tulokset ja tulosten tarkastelu}

Kantojen ja juurakoiden hankintaketjun nettoenergia oli pellonraivauksessa 446 - 698 GJ ha $^{-1}$ suoria energiapanoksia tarkasteltaessa. Vastaavasti energiasuhteet olivat 22 - 33. Kun epäsuorat energiapanokset otettiin lisäksi huomioon, niin luvut olivat vastaavasti $440-692 \mathrm{GJ}^{\text {ha-1 }} \mathrm{ja}^{17}-26$.

Hakkuutähdehakkeen hankintaketjun nettoenergia oli 386 - $566 \mathrm{GJ} \mathrm{ha}^{-1}$, ja energiasuhteet olivat 40 - 59 suoria energiapanoksia tarkasteltaessa. Kun epäsuorat energiapanokset otettiin huomioon, niin nettoenergia oli 384 - $564 \mathrm{GJ}_{\text {ha }}{ }^{-1}$, ja energiasuhteet 33 - 47. Polttoainetta kului hakkuutähdehakkeen hankinnassa vähemmän kuin kantomurskeen hankinnassa, mutta hakkuutähteen energiasisältö oli vastaavasti alempi kuin kantojen.

Metsäenergian hankinnan nettoenergiat ja energiasuhteet olivat samaa tasoa tässä tutkimuksessa kuin Laitilan ym. (2012) tutkimuksessa. Tässä tutkimuksessa epäsuorat energiapanokset huomioon ottavat tulokset olivat kuitenkin uusia eikä vertailukelpoisia tuloksia oli olemassa.

Hakkilan (1989) mukaan metsäenergian hankinnassa voidaan soveltaa traktorin valmistuksen energiapanoksia 158,9 $\mathrm{MJ} \mathrm{kg}^{-1}$, kun metsäenergian hankinnan epäsuoria energiapanoksia lasketaan. Myöhemmin Mikkola ja Ahokas (2010) sekä Mikkola (2012) käyttivät lukuarvoa 86,8 MJ kg-1 maatalouskoneiden energiapanoksena. Tässä tutkimuksessa metsäkoneiden epäsuorat energiapanokset jäivät kuitenkin alhaisiksi, koska koneiden tekninen käyttöikä oli neljä vuotta sekä kone- ja autokuljetuskaluston vuotuiset käyttötuntimäärät olivat 3000 tuntia. Sen sijaan maatalouspuolella konekaluston vuotuinen käyttötuntimäärä voi olla alhainen, mutta vähän käytetty kalusto voi ajan myötä osin teknisesti vanheta.

Kantojen ja juurakoiden hankinnassa käytettävän kaluston korjaus- ja huoltotoimenpiteiden energiapanosten osalta ei ollut lukuarvoja käytettävissä, mikä rajoitti laskelmien laatimista. Tältä osin tarvitaan aineistojen keräämistä kenttäoloissa.

Metsäautoteiden rakentamisen eikä metsänhoitotöiden energiapanoksia ei ollut käytettävissä, eikä niitä otettu siten laskelmissa huomioon. Toisaalta niiden vaikutus voidaan olettaa vakioksi, kuten peltojen salaojituksenkin peltobioenergiakasvien energiataseita laskettaessa (ks. Mikkola 2012). Myöskään energiaterminaalien energiapanoksia ei voitu määrittää puuttuvien tietojen takia. Samoin metsähakkeen ja sen mukana tapahtuva energiasisällön hävikki jäi laskelmien ulkopuolelle.

\section{Johtopäätökset}

Kantojen ja juurakoiden korjuu on osa pellonraivausta. Hakkuutähteiden sekä kantojen ja juurakoiden hankinnan nettoenergiat ja energiasuhteet olivat positiivisia. Pellonraivaajan kannattaa myydä hakkuutähteet ja kannot metsä- ja energiayhtiöille. Jotta polttohake kelpaa voimalaitoksille, kannattaa pellonraivauskohteiden metsähakkeen hankinta ulkoistaa metsä- ja energiayhtiöille.

Energiataseet ja -suhteet olivat samaa tasoa kuin aikaisemmissa tutkimuksissa. Tämä tutkimus esitti ensimmäiset epäsuorat energiapanokset huomioon ottavat laskelmat Suomen oloissa. Vertailututkimusten puute haittaisi laskelmien yleistämistä. Pellonraivauksessa käytetyn konekaluston epäsuorat energiapanokset jäävät kuitenkin alhaiseksi, kun koneiden tekniset käyttöiät ovat lyhyet ja vuotuiset käyttötuntimäärät korkeat. Kone- ja kuljetuskaluston korjauksen ja huollon energiapanosten osalta ei ollut laskentaparametreja käytettävissä, ja siltä osin tarvitaan jatkotutkimuksia. 


\section{Kiitokset}

MMT Hannu J. Mikkola antoi arvokkaita neuvoja alkuperäisen tutkimuksen englanninkieliseen käsikirjoitukseen. MMM Tuomas Hakonen ja MMM Ismo Makkonen avustivat kuvamateriaalin kanssa. KTM Ari Sivula Agrobiotalous Seinäjoesta sekä MMM Juho Lahti SeAMK Ilmajoelta auttoivat tekstin taitossa.

\section{Kirjallisuutta}

Hakkila, P. 1989. Utilization of forest residual biomass. Springer-Verlag. Berlin. $568 \mathrm{~s}$.

Hakkila, P. 2004. Puuenergian teknologiaohjelma 1999-2003. Metsähakkeen tuotantoteknologia. Loppuraportti. Tekes. Teknologiaohjelmaraportti. 5: 1-135.

Laitila, J. , Heikkilä, J. \& Anttila, P. 2010. Harvesting alternatives, accumulation and procurement cost of smalldiameter thinning wood for fuel in Central Finland. Silva Fennica 44(3): 465-480.

Laitila, J. , Asikainen, A. \& Pasanen, K. 2012. Hankinnan teknologia, logistiikka ja hiilidioksidipäästöt. Metlan työraportteja 240: 171-184. http://www.metla.fi/julkaisut/workingpapers/2012/mwp240.htm. Viitattu 16.1.2015.

Laurila, J. \& Lauhanen, R. 2007. Kannonnoston ja metsäkuljetuksen tuottavuus ja kustannukset. Teoksessa: Lauhanen, R. \& Laurila, J. (toim.) Bioenergian hankintalogistiikka. Tapaustutkimuksia Etelä-Pohjanmaalta. Seinäjoen ammattikorkeakoulun julkaisuja B33:68-92.

Laurila, J. \& Lauhanen, R. 2010. Moisture content of Norway spruce (Picea abies (L.) Karst.) stump wood at clear cutting areas and roadside storage sites. Silva Fennica 44(3): 427- 434.

Lauhanen, R. , Ahokas, J. , Esala, J. , Hakonen, T. , Sippola, H. , Viirimäki, J. , Koskiniemi, E. , Laurila, J. \& Makkonen, I. 2014. Metsätoimihenkilön energialaskuoppi. Seinäjoen ammattikorkeakoulun julkaisusarja C. Oppimateriaaleja 6: 1-167.

Mikkola, H. 2012. Peltobioenergian tuotanto Suomessa. Potentiaali, energiasuhteet ja nettoenergia. Helsingin yliopisto, Maatalous-metsätieteellinen tiedekunta. Maataloustieteiden laitos. Julkaisuja 10: 1-93.

Mikkola, H. J. \& Ahokas, J. 2010. Indirect energy input of agricultural machinery in bioenergy production. Renewable Energy 35: 23-28.

Niskanen, O. \& Lehtonen, E. 2014. Maatilojen tilusrakenne ja pellonraivaus Suomessa 2000-luvulla. Development of parcel structure and clearing of new fields in Finland in the 2000s. MTT Raportti 150: 1-27. http://www.mtt.fi/mttraportti/pdf/mttraportti150.pdf Viitattu 2.1.2015. 